This PDF is a selection from an out-of-print volume from the National Bureau of Economic Research

Volume Title: Factors Influencing Consumption: An Experimental Analysis of Shoe Buying

Volume Author/Editor: Ruth P. Mack

Volume Publisher: NBER

Volume ISBN: 0-87014-416-2

Volume URL: http://www.nber.org/books/mack54-1

Publication Date: 1954

Chapter Title: Changes in the Distribution of Income

Chapter Author: Ruth P. Mack

Chapter URL: http://www.nber.org/chapters/c9373

Chapter pages in book: (p. 14 - 19) 


\section{CHANGES IN THE DISTRIBUTION OF INCOME}

We have been speaking of the influence of changes in aggregate income of American consumers on their shoe purchasing, but it might make a considerable difference in this context if account were taken of which American consumers whether rich or poor, farmers or city folk, white collar or factory workers.

\section{Income Size Distribution}

The importance of change in size distribution of income in explaining changes in shoe buying depends on the difference at any one time in the extent to which change in income affects the shoe buying of families with incomes at various

shoes for families, though and expenditure studies give the amount spent on income level in Table 2. The for single individuals. The figures are shown by income rises, as would necessarily follo of income spent on shoes declines as income would still, on the average, buy from the fact that families having no the declining percentage is due to the curvatur. But columns 7 and 8 show that sion of shoe buying on income. unchanged aggregate income, other means that shifts in distribution of an buying: over twice as much sher things the same, would affect total shoe a dollar added to the income of ayying, the table indicates, would result from the highest two. Thus the suf a family in the lowest two income groups as in had varied substantially over the suggests that if income distribution actually a perceptible influence on shoe buying. A recent study of income size distrib.

annual estimates of the proportion distribution by Simon Kuznets has developed population having the top 5 per cen income received by the segment of the tion for the top 5 per cent of the cent per capita incomes. ${ }^{1}$ Of course, informaperiod, is less adequate as a basis of studion, which is all that is available for the bution on shoe expenditure. and indudying the impact of changing size distrisince the top 5 per cent of the fandeed on most expenditures, than on saving, proportion of the net saving for the councome distribution did a very large to the 1935-1936 survey - and only a small - around 80 per cent, according the table suggests perhaps 15 per cent. ${ }^{2}$.

${ }^{2}$ Simon Kuznets, assisted by Elizher

Savings (National Bureau of Economic Research, 1953). Upper Income Groups in Income and

94,000 in the top income class and another 
Kuznets found that the proportion of total country-wide income received by the top 5 per cent of the population rose from 1920 to 1928 and then fell through 1944 - abruptly during the war years. The percentages of aggregate disposable income received by the top 5 per cent were 24 per cent in 1920, 34 per cent in 1928, 25 per cent in 1940, and 16 percent in 1944. Fitting a straight line to the data for 1926-1941, we find that the percentage of income received by the top 5 per cent of the population fell between 1926 and 1941 by almost 10 points - that is, from about 34 per cent to around 24.5 per cent. The deviations from the line of trend were seldom more than \pm 1 percentage point. It would be highly desirable to be able to learn from area surveys whether changes of this magnitude might have a tangible impact on shoe buying.

All that can be done is to use the 1935-1936 data to see what the impact would be with three large "ifs": (1) if the figures are accurate representations of the situation in 1935-1936; (2) if they are applicable to other times; (3) if change through time follows the pattern of interfamily differences at one time. We know of course that at best the conditions could be met only in a highly approximate fashion; whether the approximation is even close enough to provide estimates of the proper order of magnitude cannot be said. The procedure is beset not only by the usual problems about the meaning of income sensitivity of spending based on area surveys and its applicability to change over time but, in addition, by special problems associated with group standards and their influence on individual behavior when income distribution shifts. In spite of this skepticism it may be worthwhile to make the calculations and see what they say. We compute separately the trend impact and that of the deviation around the trend.

Let us assume that relative income distribution within the lower 95 per cent and within the upper 5 per cent of the families remained fixed as disclosed by the 1935-1936 survey, but the proportion received by the two segments shifted between 1926 and 1941 in accordance with the trend disclosed in Kuznets' figures for the top 5 per cent of the population.' From Table 2, column 8, we compute the average change in shoe buying accompanying a change in income of $\$ 100$ for the lower and upper segments of the distribution. For the lower 95 per cent it is $\$ 1.23$ and for the upper 5 per cent it is $\$ .60 .^{5}$ In the fifteen-

676,000 from the $1,585,000$ families in the next income class. Column 5 of the table suggests about how much shoe buying these $1,470,000$ families might be doing $-\$ 77.0$ million plus around a half of $\$ 74.6$ million. Single individuals, for whom no information on shoe buying was collected, are not included in these figures.

- Kuznets, op. cit., p. 637, Table 122.

'Note that Kuznets' calculations refer to population, whereas the survey data refer to families and thus are, for this reason and others, by no means strictly comparable.

- Half the \$3,000-\$5,000 income group falls in the upper and half in the lower group. The calculation is made for the lower incomes by multiplying the marginal propensities in col. 8 for all income groups under $\$ 5,000$ by the corresponding aggregate income in col. 1 , except for the $\$ 3,000-\$ 5,000$ group, which was multiplied by half the income. The figures were summed, divided by total income for these groups, and multiplied by 100 . The corresponding calculation for the two upper groups gave the second figure. 


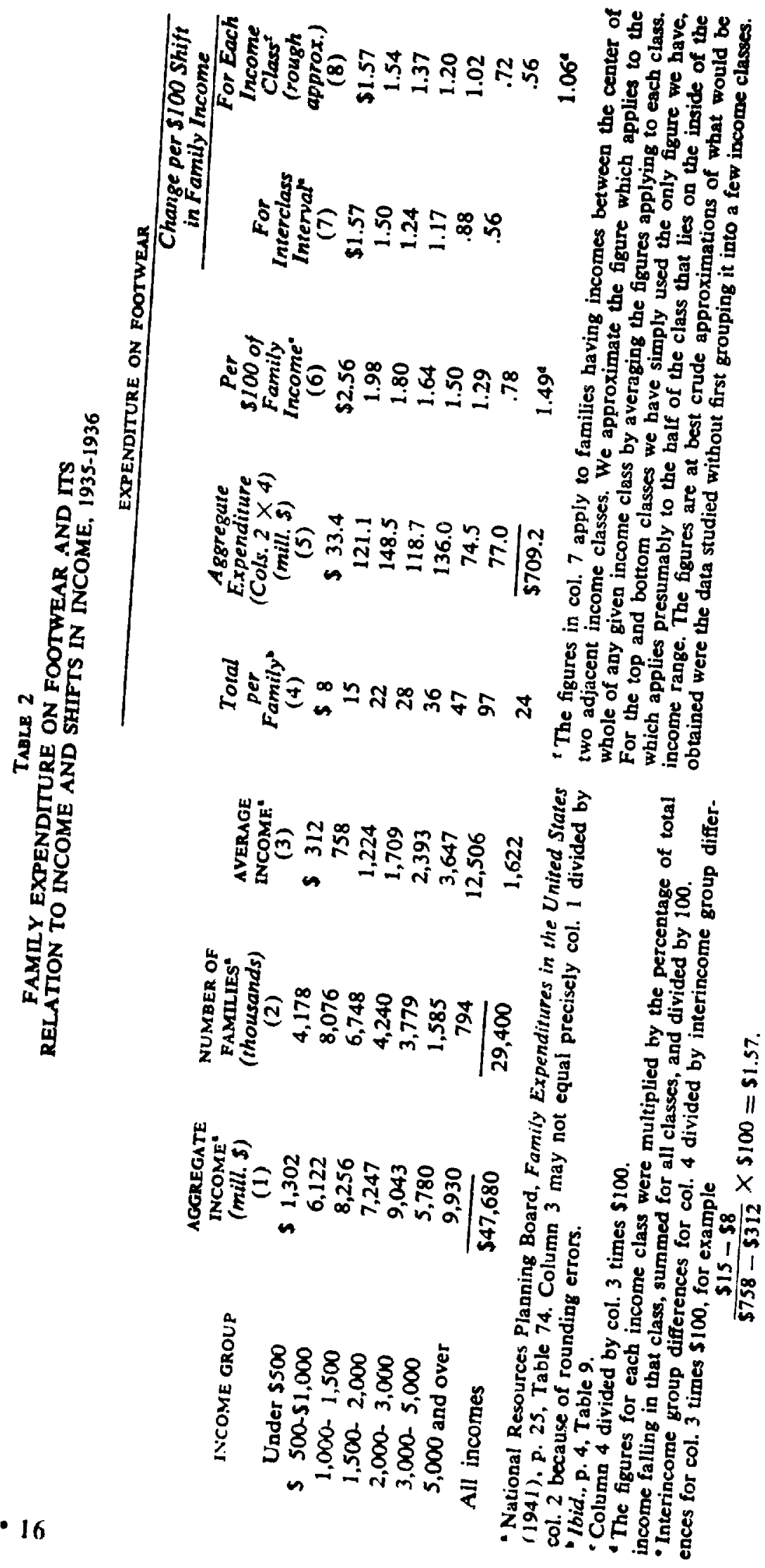


year interval 1926-1941 the proportion of income received by the lower income group rose by 9.5 percentage points. For each percentage point shift in income distribution, shoe buying would have increased by $\$ .0123$ and decreased by $\$ .0060$, a net gain of $\$ .0063$, which for 9.5 percentage points comes to $\$ .0599$. Since in 1935-1936 a total of $\$ 1.49$ was spent on shoes for every $\$ 100$ of income (col. 6, last line), the increase over the period would have amounted to 4.02 per cent of the 1935-1936 figure, or .27 per cent a year, over the fifteenyear interval.

An analogous calculation based on the same assumptions serves to estimate the extent to which shoe buying might have been affected by deviations in income distribution around its line of trend, which were in only two cases more than \pm 1 percentage point (they average .5 for the period that we can examine with the aid of time series). Were the trend separately accounted for, shoe buying would, on the basis of the survey data, have shifted by a maximum of \pm .4 per cent of the 1935-1936 figure, as per cent of income going to the upper 5 per cent shifted \pm 1 percentage point. ${ }^{\circ}$

As suggested at the outset, it is hard to say just what these calculations show. One would expect that the upward trend of the share of income received by the lower 95 per cent would make itself felt. But actually the net trend in shoe buying - if other things, including aggregate income, be separately accounted for - was, as we shall see, down, not up. In other words, other factors making for a reduction in dollars spent on shoes more than compensated for the upward trend that might have followed in the wake of less inequality of income distribution. The deviation from the trend may well be so small that it might be ignored. But factory payrolls do show a provocative similarity to shoe buying, especially in the short movements. Besides, our estimates of shoe sales may, the Appendix indicates, overrepresent the buying of factory workers. Consequently, it seems well to leave the matter open for further examination in a regression scheme.

In any event these calculations indicate that the relatively small impact of size distribution (other than the trend influence which cannot be isolated) is a function of the small experienced change (other than long-term trend) rather than, as far as we know, an insensitivity of marginal shoe buying to the size of family income. Were a period to come when there were substantial changes in the concentration of income of a sort that could be separated from other influences, palpable changes in shoe buying, ceteriv paribus - or indeed in the buying of any other commodity equally sensitive to income distribution might follow. The war years would certainly qualify as such a period, judging from Kuznets' tables for 1942 on. Any effort to project prewar conditions into postwar shoe markets would therefore have to make allowances for the decrease in the concentration of income that took place.

\footnotetext{
- Following the previous calculation, $.0123-.0060=.0063$. Deviations of this size amount to \pm .42 per cent of 1.49 . the $1935-1936$ average figure. Incidentally. if we make the extreme assumption that the whole shift occurred between the two extreme income groups, the total effect is still only \pm .7 per cent.
} 
Contrasts in the association between income and expenditure for shoes of farm and urban families appear in the data collected in 1935-1936. The figures are given in Table 3. Columns 3 and 4 slow that poorer farm families spend a larger, and wealthier families a smaller, percentage of farm families than city families at the same income level ${ }^{8}$ The show that the regression of shoe buying on ${ }^{8}$ The last two columns ( 7 and 8 ) ing on income is less steep for farm than cases. This means that shoe buying wor end of the range, and is bowed in both tion of income within each groung would be affected by a shift in the distribu-

From 1926 to 1941 the proup as well as by a shift between the two groups. and their employees ranged between of total personal income goilg to farmers (in 1935). If the size distribeen 6.3 per cent (in 1932) and 10.9 per cent the urban sector remained the of income within the farm sector and within shift in over-all income size disame as that shown in the 1935-1936 study, a income shifts between the distribution would have occurred as a result of the spending patterns for each inctors. In that case, assuming that the 1935-1936 the period, then out of everycome class applied to a shift in income throughout a cent less would have been $\$ 100$ of aggregate national personal income, .9 of have amounted to about spent on shoes in 1935 than in 1932, and this would hand, the relative incomt .6 per cent of aggregate shoe buying. If, on the other change, a shift in size distribution whion for the population as a whole did not and within the urban sector. farm population would hav. In that case the shift in income in - about 1.7 cents per have been somewhat larger in income in favor of the buying. about 1.1 per cent of aggregate shoe 'Il seems pobate that inat no other diffe city families. See for that income as calculated in the Curves of Farm Families," Confereareet Reid, "Bffect is not truly comparable for however, there volume Fifticen (Nationce on Research in of Income Concept upon for farm and - Parm familics seems to be no adequate way of Economic Researthealth. Studies in inditure families bilics spend a smaller puate way ont of the difficulty. cols. 5 and 6 .

arger part of total consumption of furns the a larger one than city all other income with income was spent in acty families. Sce

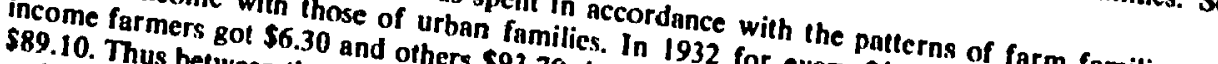
and the others between the two years $\$ 93.70$; in 1935 the cor every $\$ 100$ of aggreg families and farm families wost \$4.60. The years, out of every $\$ 100$ of corresponding figures were consumer The marginal was .9.4 per cent (Table shoe buying propengregate income farmers $\$ 10.90$ and less. The net diffensity for city famile 3. col. 8. last line); (hity for the weighted gained \$4.60 the country as a whee was \$.009 per $\$ 100$, 1.14 per cent: the fore, farners spent soge of all amounted to as a whole was $\$ 1.49$ per $\$ 100$ of income. In t therefore, city families $\$ .043$ more.

If, instead of at .6 per cent of agere $\$ 100$ of income (se35-1936, average sties spent \$.052 unaliered, we of assuming that the income shoe buying. (see Table 2, col. 6). The buying for lost a proportiosume that when city isome distribution with in the $\$ 1,000-1,500$ share of the total drop in having inconnes the farm and cily familios weighted marginal propensity for were the beneficiaries, for cily families, it was $\$ 1,0 \% 0$ and $\$ 1,500$ . Consequently, the shift of $\$ 4,60$ (weighted by the city in all income classamilies 


\section{TABLB 3 \\ THE RELATION OF SHOE BUYNG TO INCOME OF FARM AND OF URBAN FAMILIES, 1935-1936}

\begin{tabular}{|c|c|c|c|c|c|c|c|c|c|}
\hline \multirow{2}{*}{\multicolumn{2}{|c|}{ INCOME RANOE }} & \multicolumn{2}{|c|}{$\begin{array}{c}\text { \% OP ALL IN- } \\
\text { COME RECEIVED } \\
\text { BY PAMILIES IN } \\
\text { EACH INCOME } \\
\text { GROUP }\end{array}$} & \multicolumn{2}{|c|}{$\begin{array}{c}\text { \% OP } \\
\text { INCOME SPENT } \\
\text { ON POOTWEAR }\end{array}$} & \multicolumn{2}{|c|}{$\begin{array}{l}\text { \% OF TOTAL } \\
\text { OUTLAY SPENT } \\
\text { ON FOOTWEAR }\end{array}$} & \multicolumn{2}{|c|}{$\begin{array}{l}\text { \% OF SHIFT IN } \\
\text { INCOME SPENT } \\
\text { ON FOOTWEAR }\end{array}$} \\
\hline & & $\begin{array}{l}\text { Urban } \\
\text { (1) }\end{array}$ & $\begin{array}{c}\text { Farm } \\
\text { (2) }\end{array}$ & $\begin{array}{c}U, \sin \\
\text { (3) }\end{array}$ & $\begin{array}{c}\text { Farm } \\
\text { (4) }\end{array}$ & $\begin{array}{c}\text { Urban } \\
\text { (5) }\end{array}$ & $\begin{array}{c}\text { Farm } \\
(6)\end{array}$ & $\begin{array}{c}\text { Urban } \\
(7)\end{array}$ & $\begin{array}{c}\text { Farm } \\
(8)\end{array}$ \\
\hline Under & $\$ 50$ & 1.4 & 5.0 & 2.74 & 3.54 & 1.52 & 2.23 & 1.30 & 1.21 \\
\hline $500-\$$ & 1,000 & 9.2 & 21.8 & 1.90 & 2.26 & 1.75 & 2.0 & 1.31 & 1.3 \\
\hline 1,000 & 1,500 & 17.4 & 23.4 & 1.69 & 1.95 & 1.69 & 2.04 & 1.46 & 1.2 \\
\hline 1,500 & 2,000 & 19.0 & 17.1 & 1.66 & 1.69 & 1.75 & 1.9 & 1.40 & 8 \\
\hline 2,000 & 3,000 & 25.5 & 16.8 & 1.53 & 1.42 & 1.70 & 1.9 & 1.06 & 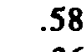 \\
\hline 3,000 & 5,000 & 17.5 & 10.3 & 1.32 & 1.08 & 1.61 & 1.7 & .74 & .3 \\
\hline 5,000 & 10,000 & 10.1 & 5.7 & .97 & .73 & 1.33 & 1.63 & .56 & \\
\hline 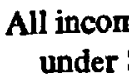 & nes & 0.0 & 100.0 & $1.54^{\circ}$ & $1.81^{\circ}$ & $1.66^{\circ}$ & $2.02^{\mathrm{d}}$ & $1.14^{t}$ & \\
\hline
\end{tabular}

- Calculations are based on data from National Resources Planning Board, Family Expenditures in the United States (1941), pp. 7 and 8, tables 20 and 21. All the figures in this table refer to families that did not receive relief during the survey year, and the income received by families with incomes of over $\$ \mathbf{1 0 , 0 0 0}$ is not included.

- Shoe expenditure for families in each income range was calculated from detailed information on clothing purchases supplied by 150,000 family members and single individuals. It is published in ibid., Tables 151 and 185. We have used these data in conjunction with statistics on the income and total outlay of nonrelief families given in the same volume, Table 21. Information from the source cited in note a was also used to make certain income and expenditure groups comparable. Aggregate expenditure on footwear for all families with incomes under $\$ 10,000$ divided by aggregate income.

Aggregate expenditure on footwear for all families with incomes under $\$ 10,000$ divided by aggregate expenditure on all consumption.

- Interclass shift in shoe buying divided by interclass shift in income and averaged for upward and downward shift. The computation was analogous to that shown in Table 2, note d.

I Marginal propensities applicable to each income class weighted by the proportion of aggregate income received by that class (col. 1 or 2 ) and divided by the sum of the weights.

people would be so strong as the farm-urban one. Though it seems likely that manual workers would spend more on shoes than would clerical workers, we simply have as yet no adequate information to go by. ${ }^{10}$

On the basis of these rough explorations we certainly cannot dismiss the possibility that shoe sales would be adversely affected in years when there was a shift of income both toward rural pursuits and toward upper income brackets, whereas a year in which low-income urban manual workers fared well might cause shoe sales to be perceptibly better at any given level of aggregate income. The efforts to test this proposition by the use of time series are discussed later.

decreased city shoe spending by $\$ .052$, as before, families would, under these assumptions, have decreased but increased farm spending by only .0076 times $\$ 4.60$, or $\$ .035$ - a net decrease of $\$ .017$. This shift amounted to $\$ .017$ divided by $\$ 1.49$, or 1.1 per cent of shoe buying.

- The information on income and spending of individual families in 1935-1936 was classified by the occupation of the head of the family, and some differences do seem to appear on the average in the proportion of income spent and saved at various income levels by wage earners', clerical, and businessmen's families. But even these differences cannot be assigned to the occupational factor with certainty. As to the relevant difference for the present purpose - difference in marginal spending patterns - very little can be said. 